\title{
Neuroendoscopic surgery for unilateral hydrocephalus due to inflammatory obstruction of the Monro foramen
}

\author{
Francisco A. Vaz-Guimarães Filho', Clauder O. Ramalho², \\ Ítalo C. Suriano ${ }^{3}$, Samuel T. Zymberg ${ }^{4}$, Sérgio Cavalheiro ${ }^{4}$
}

\begin{abstract}
Objective: Unilateral hydrocephalus $(\mathrm{UH})$ is characterized by enlargement of just one lateral ventricle. In this paper, the authors will demonstrate their experiences in the neuroendoscopic management of this uncommon type of hydrocephalus. Method: The authors retrospectively reviewed a serie of almost 800 neuroendoscopic procedures performed from September 1995 to July 2010 and selected seven adult patients with UH. Clinical and radiological charts were reviewed and analyzed. Results: Six patients had intraventricular neurocysticercosis and one patient had congenital stenosis of the foramen of Monro. Headaches were the most common symptom. A septostomy restored cerebrospinal fluid circulation. During follow-up period (65.5 months, range 3-109) no patient has presented clinical recurrence as well as no severe complications have been observed. Conclusion: $\mathrm{UH}$ is a rare condition. A successful treatment can be accomplished through a neuroendoscopic approach avoiding the use of ventricular shunts.
\end{abstract}

Key words: foramen of Monro, unilateral hydrocephalus, neuroendoscopy, neurocysticercosis.

Cirurgia neuroendoscópica para tratamento da hidrocefalia unilateral secundária à obstrução inflamatória do forame de Monro

\section{RESUMO}

Objetivo: Hidrocefalia unilateral (HU) é caracterizada pelo alargamento de apenas um dos ventrículos laterais. Neste estudo, os autores demonstraram sua experiência no manejo deste tipo incomum de hidrocefalia. Método: Foram revisados, de uma série de quase 800 cirurgias neuroendoscópicas realizadas entre Setembro de 1995 e Julho de 2010, sete pacientes adultos com diagnóstico de HU. Dados clínicos e radiológicos foram analisados. Resultados: Seis pacientes tinham neurocisticercose intraventricular e um apresentava uma estenose congênita do forame de Monro. Cefaléia foi o sintoma clínico mais comum. Uma septostomia restabeleceu o fluxo liquórico. Durante o seguimento (65,5 meses, de 3-109), nenhum paciente apresentou recorrência clínica assim como nenhuma complicação grave foi observada. Conclusão: HU é uma condição rara. $\mathrm{O}$ tratamento

\section{Correspondence}

Francisco de Assis Vaz-Guimarães Filho Rua Doutor Diogo de Faria 1202 / cj. 31 04037-004 São Paulo SP - Brasil

E-mail: vazguimaraes.neuro@gmail.com

Received 29 June 2010

Received in final form 4 November 2010

Accepted 12 November 2010 satisfatório pode ser alcançado por meio de uma abordagem neuroendoscópica evitando, desta maneira, o uso de sistemas de derivação ventricular.

Palavras-chave: forame de Monro, hidrocefalia unilateral, neuroendoscopia, neurocisticercose.

Department of Neurology and Neurosurgery, Division of Neurosurgery, Federal University of São Paulo, São Paulo SP, Brazil: ${ }^{1} \mathrm{MD}$, Assistant Neurosurgeon; ${ }^{2} \mathrm{MD}$, Resident in Neurosurgery; ${ }^{3} \mathrm{MSc}$, Staff Neurosurgeon; ${ }^{4} \mathrm{PhD}$, Professor of Neurosurgery. 
Blockage of normal cerebrospinal fluid (CSF) pathways causing obstructive hydrocephalus is often a lifethreatening condition. Most cases present as acute intracranial hypertension syndrome. To date, neuroendoscopic management is considered the "gold-standard" treatment ${ }^{1}$.

Different etiologies could be responsible for this blockage. Neoplastic, infectious, vascular and congenital diseases can interrupt the CSF flow at any point of the ventricular system ${ }^{1-3}$. By neuroendoscopic means, the neurosurgeon can create an "artificial" pathway that restores CSF circulation ${ }^{4}$.

If the site of obstruction is located in the third or fourth ventricles, enlargement of both lateral ventricles will occur. Otherwise, if the blockage is located around one of the foramen of Monro, an enlargement of just one lateral ventricle will occur ${ }^{5-11}$. This condition is recognized as unilateral hydrocephalus (UH). The clinical manifestations are commonly mild or slowly progressive and the diagnosis is often delayed.

Treatment of UH includes ventricular shunting ${ }^{8}$ and neuroendoscopic approach ${ }^{4,5,7}$ through fenestration of the septum pellucidum or foraminal plasty of the foramen of Monro ${ }^{12}$.

In this paper, the authors will demonstrate their experience in the neuroendoscopic management of this uncommon type of hydrocephalus in adult patients and discuss relevant clinical and surgical data.

\section{METHOD}

In the Division of Neurosurgery of Federal University of São Paulo, almost 800 patients underwent neuroendoscopic surgery between September 1995 and July 2010. From this group, we identified seven adult patients (four females and three males, mean age 41 years, range 22-72 years) with the diagnosis of UH. Medical charts were reviewed and clinical data analyzed (Table 1). UH in pediatric patients was not included because, in the author's opinion, the main etiologies (posthemorrhagic, congenital abnormalities) should be discussed in another specific study.
All patients had radiologic evaluation with magnetic resonance imaging (MRI). Enlargement of one lateral ventricle confirmed the diagnosis of UH. At this point, special attention was directed to find out the cause of the ventriculomegaly.

All patients underwent neuroendoscopic surgery. The entry point was determined by the side of the ventricular enlargement. Furthermore, this point was located $2 \mathrm{~cm}$ anterior to coronal suture and related with the external orbital line. This position could provide a more comfortable approach to the midline structures (foramen of Monro, septum pellucidum).

After tapping ventricular cavity, a rigid 0-degree neuroendoscope was inserted and ventricular anatomy recognized by direct observation. The foramen of Monro and the septum pellucidum were carefully examined and the surgical decision (fenestration or plasty) made. Postoperative follow-up was accomplished with MRI and clinical evaluation. All patients signed an informed consent for this study.

\section{RESULTS}

Six patients had intraventricular neurocysticercosis and one patient had congenital stenosis of the foramen of Monro. Headaches were the most common clinical presentation (six patients) followed by vertigo (four patients) and papiledema (three patients). The time from initial clinical manifestations to diagnosis was 11 months (range 6-20 months). MRI studies showed unilateral ventricular enlargement with signs of increased pressure such as a shifting of the septum pellucidum and CSF periventricular transudation.

In one patient with cysticercosis, the cyst was loose in the ventricular cavity and easily removed. On the other hand, one patient developed UH after medical treatment of neurocysticercosis. During surgical procedure, a thin membrane was identified in the region of the foramen of Monro leading to ventricular enlargement (Fig 1). A septostomy and a foraminal plasty were performed. In the other four cases the cysts were firmly adherent to

Table 1. Clinical data.

\begin{tabular}{|c|c|c|c|c|}
\hline & Pathology & Ventriculomegaly & Clinical presentation & $\Delta t$ to diagnosis \\
\hline Fem., 42 yo & Cysticercosis & Right side & Headache, Vertigo & 13 months \\
\hline Fem., 23 yo & Cysticercosis & Right side & Headache, Vertigo, Papiledema & 10 months \\
\hline Male, 22 yo & Cysticercosis & Right side & Headache, Papiledema & 8 months \\
\hline Fem., 72 yo & Cysticercosis & Left side & Headache, Vertigo & 20 months \\
\hline Male, 39 yo & Cysticercosis & Right side & Headache, Papiledema & 9 months \\
\hline Fem., 42 yo & Cong. stenosis & Left side & Headache, Vertigo & 6 months \\
\hline Male, 47 yo & Cysticercosis & Right side & Headache, Vertigo & 9 months \\
\hline
\end{tabular}

Fem.: female; yo: years-old; $\Delta$ t: time from first symptoms. 


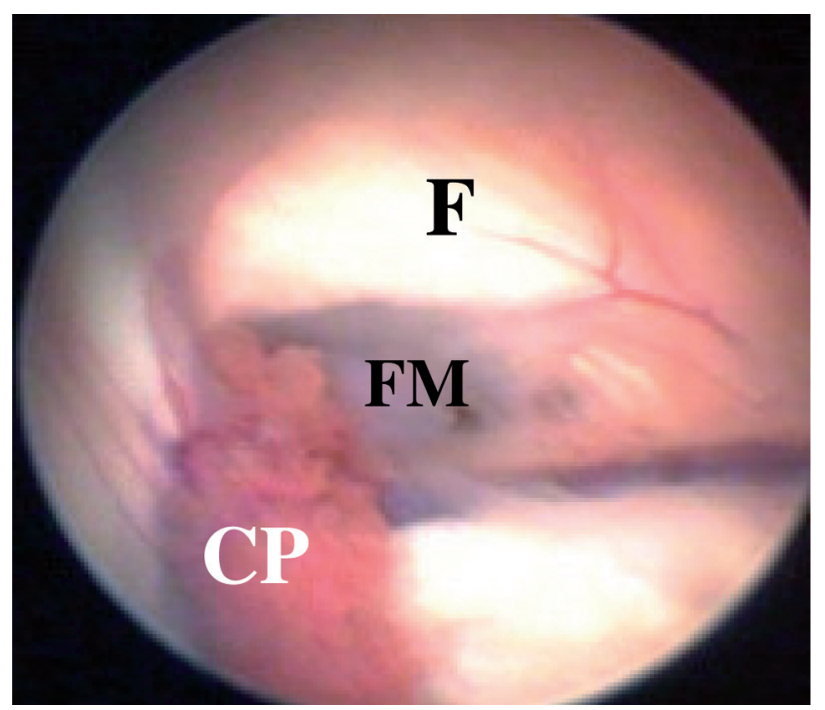

Fig 1. Surgical view of the right foramen of Monro. Note a thin membrane in the region of the foramen blocking the CSF flow. F: Fornix; FM: Foramen of Monro; CP: Choroidal plexus.

ependima. A septostomy restored CSF circulation. The only case with no cysticercotical disease, a constricted foramen was observed and a septostomy performed.

Operative time was 23.4 minutes (range 15-30 minutes). The length of hospitalization was three days (2-5
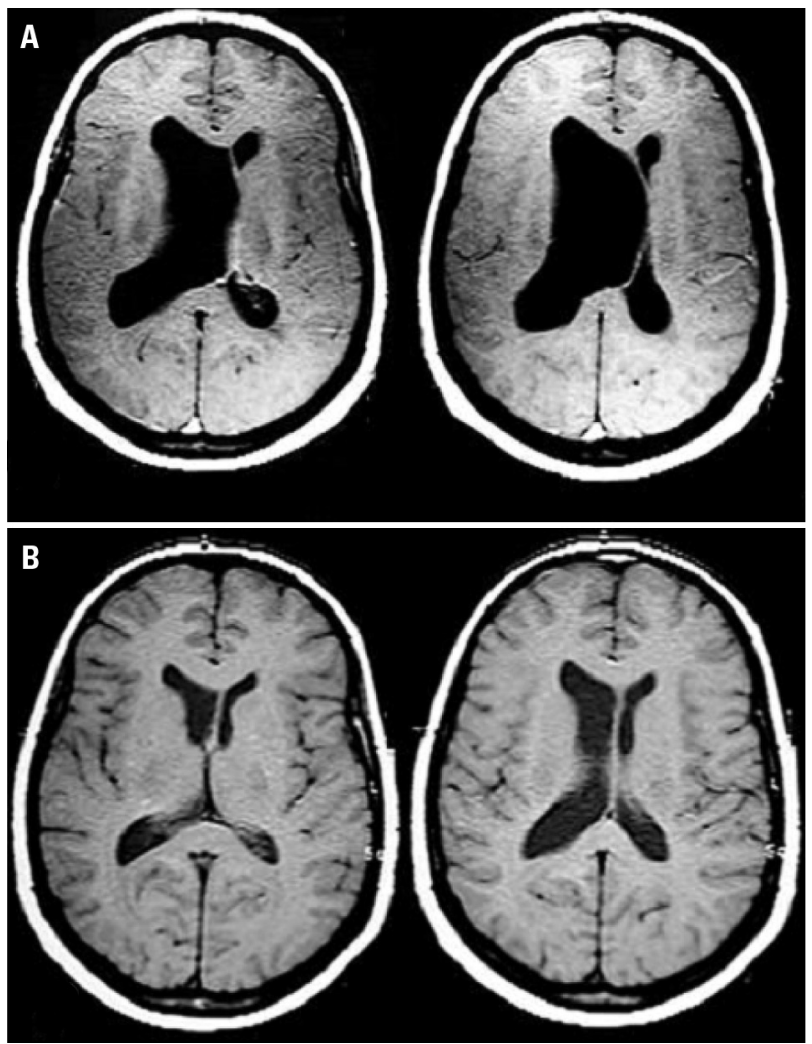

Fig 2. Unilateral hydrocephalus due to intraventricular neurocysticercosis. [A] Preoperative MRI; [B] Postoperative MRI.

Table 2. Surgical data.

\begin{tabular}{lccc}
\hline & Surgical procedure & Operative time & Hospitalization \\
\hline Fem., 42 yo & Cyst removed & 15 minutes & 2 days \\
Fem., 23 yo & Septostomy & 30 minutes & 2 days \\
Male, 22 yo & Septostomy & 18 minutes & 4 days \\
Fem., 72 yo & Septostomy & 27 minutes & 5 days \\
Male, 39 yo & Septostomy & 26 minutes & 2 days \\
Fem., 42 yo & Septostomy & 28 minutes & 3 days \\
Male, 47 yo & Septostomy & 20 minutes & 2 days \\
& Foraminal plasty & & \\
\hline
\end{tabular}

Fem.: female; yo: years-old

Table 3. Postoperative evaluation.

\begin{tabular}{llccc}
\hline & Clinical findings & Complications & MRI findings & Follow-up \\
\hline Fem., 42 yo & Asymptomatic & No & VE & 109 months \\
Fem., 23 yo & Asymptomatic & No & VE & 101 months \\
Male, 22 yo & Asymptomatic & No & VE decreased & 92 months \\
Fem., 72 yo & Asymptomatic & No & VE & 78 months \\
Male, 39 yo & Asymptomatic & No & VE & 66 months \\
Fem., 42 yo & Asymptomatic & No & VE decreased & 10 months \\
Male, 47yo & Asymptomatic & No & VE decreased & 3 months \\
\hline
\end{tabular}

Fem.: female; yo: years-old; VE: ventriculomegaly. 


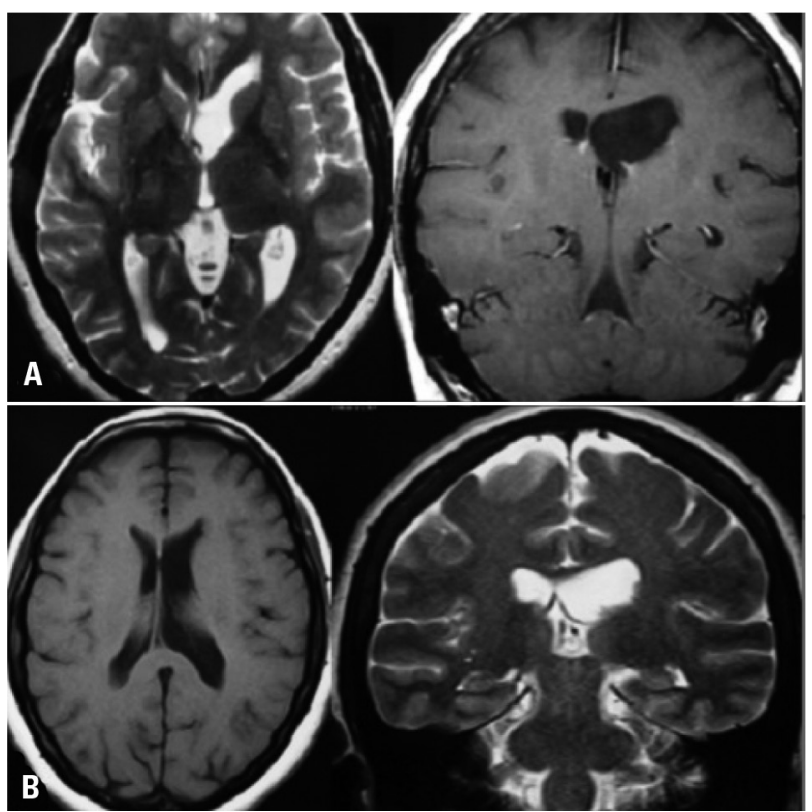

Fig 3. Unilateral hydrocephalus due to congenital stenosis of foramen of Monro. [A] Preoperative MRI; [B] Postoperative MRI.

days). Mild headaches, vomiting and vertigo during first 48 hours after surgery were the main postoperative complains. Table 2 shows surgical data.

During follow-up period (65.5 months, range 3-109) no patient has presented clinical recurrence as well as no severe complications have been observed. Postoperative MRI showed variable finds, with maintenance of ventricular enlargement in four cases and decrease in three (Table 3). However, shifting of the septum pellucidum and periventricular transudation disappeared in all patients six months after the surgery (Figs 2 and 3).

\section{DISCUSSION}

Hydrocephalus is one of the most common clinical situations that lead to neurosurgical intervention ${ }^{1,2}$. Otherwise, $\mathrm{UH}$ is rarely reported. Its treatment includes ventricular shunting or neuroendoscopic surgery ${ }^{4-8}$.

In the pediatric population, posthemorrhagic and congenital abnormalities are more commonly described than the adult population ${ }^{3,13}$. We believe that the best treatment option includes a multiprofessional and individualized approach. The neuroendoscope plays an important role but should be considered in association with others techniques in most cases.

Oi's proposed classification ${ }^{14}$, considered UH in four different categories according the appearance of the foramen of Monro: [1] atresia; [2] morphological obstruction; [3] functional obstruction; and [4] patent foramen. This classification can be easily applied to evaluate preoperative MRI findings. In our series we found six cases of morphological obstruction and one case of atresia.
Several different endoscopic approaches are amenable to treat $\mathrm{UH}^{5,9,15,16}$. The neuroendoscope can be introduced into the enlarged or even the contralateral normal ventricle. Furthermore, both frontal and occipital horn can be used as part of the surgical trajectory. The choice of the one or the other will depend on the experience of the neurosurgeon and the preoperative planning. Undoubtly, neuronavigation can greatly help surgical planning and, if available, should always be used ${ }^{11}$.

Some authors recommend an approach through the occipital horn of the contralateral normal ventricle? They referred that the fenestration of the septum pellucidum could be easily performed and that the surgical trajectory is safer than the dilated frontal approach.

Foraminal plasty of the foramen of Monro can also be applied to treat $\mathrm{UH}^{12}$. Fenestration of the constricted foramen can be done with many different instruments (Fogarty catheter, grasp forceps, biopsy forceps, laser). After that, dilatation is commonly done with microballoon.

In fact, UH represented a small number of our patients (less than $1 \%$ of operated cases). Neuronavigation system was available in only one patient (foraminal congenital stenosis). For this reason, surgical planning of the other six cases was conducted carefully based on MRI findings.

We suggest that the frontal horn is more easily approached than the occipital horn. Most neuroendoscopic procedures are performed through the frontal horn approach such as thirdventriculostomy, resection of colloid cysts and fenestration of most arachnoidal cysts. However, to make the approach to the midline structures more comfortable, we set the entry point in a slight lateral position, related with the external orbital line. In our opinion this trajectory is shorter than the occipital route and straight forward.

In our group, all patients were approached through the enlarged ventricle. We suggest that this approach increases the neuroendoscope's range of motion and could make iatrogenic lesions less common because of the larger ventricular cavity.

However, contralateral structures could be damaged during perforation of the septum pellucidum because of the narrow space ${ }^{9,15}$. To avoid this, we recommend the withdrawal of a small account of CSF. This maneuver decreases the pressure gradient between the ventricular cavities allowing the septum pellucidum to shift back and enlarging the contralateral side. At this point, perforation can be done safely.

The site of fenestration of the septum pellucidum was easily determined in our patients. Non-transparent septum pellucidum can be a problem to determine this site. Otherwise, in cases of chronic hydrocephalus such as $\mathrm{UH}$, the higher pressure often makes the septum thin 
and transparent. In our series, probably because the delay of diagnosis (mean time 11 months) every site of fenestration was easily determined.

Vinas and cols., published an excellent manuscript about the anatomy of the septum pellucidum ${ }^{17}$. They divided the septum into a frontal and an atrial segment and analyzed its vascularization. They found a bigger avascular area located anterior to the foramen of Monro and inferior to the anterior septal vein. However, we think that perforation at this site is technically challenging. So, we performed the septostomy in an area usually located just posterior to the anterior septal vein.

As we explained before, structures of the contralateral ventricle were easily identified and iatrogenic injuries avoided. The perforations were made with monopolar coagulation and enlargement with a 4-french Fogarty catheter. After that, the neuroendoscope was inserted into contralateral ventricle through this opening. This simple maneuver enlarge the opening even more and makes further examination of the contralateral ventricle safer. Smooth motion of the boundaries of the ostomy confirms its patency and is easily recognized.

We have performed only one single foraminal plasty. In our own experience, fornix manipulation should be avoided whenever possible because of the risk of cognitive impairment. Furthermore, septostomy is a safe and efficient technique to restore CSF circulation in cases of $\mathrm{UH}^{4,5,9-11,13-16}$. We suggest that foraminal plasty should be applied in very few selected cases. In our group of almost 800 operated patients, we submitted some pediatric patients to this modality of treatment with variable results.

Unilateral hydrocephalus is a rare condition. Morphological obstruction of the foramen of Monro was the most common cause in our series. Careful surgical planning and neuroendoscopic approach performed by experienced neurosurgeons are the key to a successful treatment.

In spite of many endoscopic approaches, we suggest that the experience of the neurosurgeon should guide which approach could be used. Fenestration of the septum pellucidum is safe and effective to treat $\mathrm{UH}$. Foraminal plasty of the foramen of Monro and ventricular shunting should be used as a second option in selected cases.

\section{REFERENCES}

1. Cappabianca P. Application of neuroendoscopy to intraventricular lesions. Neurosurgery 2008;62 (Suppl 2):S575-S598.

2. Zymberg ST, Marinello JLP, Vaz-Guimarães Filho FA, Cavalheiro S. Endoscopic third ventriculostomy. Braz J Neurosurg 2008;19:42-47.

3. Schulman $\mathrm{H}$, Landau D, Schulman P, Hertzanu Y. Congenital unilateral hydrocephalus: CT findings. Eur J Radiol 2000;36:161-164.

4. Oi S, Hidaka M, Honda Y, et al. Neuroendoscopic surgery for specific forms of hydrocephalus. Child's Nerv Syst 1999;15:56-68.

5. Freppel S, Marchal JC, Joud A, Pinelli C, Klein O. Early surgical management of antenatal diagnosed cystic lesions of the foramen of Monro causing monoventricular hydrocephalus. Child's Nerv Syst 2009;25:1131-1135.

6. Radaideh MM, Leeds NE, Kumar AJ, Bruner JM, Sawaya R. Unusual small choroid plexus cyst obstructing the foramen of Monro: case report. Am J Neuroradiol 2002;23:841-843.

7. Abderrahmen K, Aouidj ML, Kallel J, Zammel I, Khaldi MM. Hydrocephalus due to non tumoral stenosis of foramen of Monro: report of four cases. Neurochirurgie 2008;54:72-78.

8. Dastgir G, Awad A, Salam A, Attia M. Unilateral hydrocephalus due to foramen of Monro stenosis. Minim Invas Neurosurg 2006;49:184-186.

9. Gangemi M, Maiuri F, Donati PA, Signorelli F, Basile D. Endoscopic surgery for monoventricular hydrocephalus. Surg Neurol 1999;52:246-251.

10. Leonardo J, Grand W. Enlarged thalamostriate vein causing unilateral Monro foramen obstruction. Case report. J Neurosurg Pediatr. 2009;3: 507-510.

11. Aydin K, Cokluk C, Gokce E, et al. Use of 3DFT-CISS sequences and virtual MR endoscopy for the neuroendoscopic treatment of the unilateral hydrocephalus: case illustration. Minim Invas Neurosurg 2007:50:239-242.

12. Oi S, Enchev Y. Neuroendoscopic foraminal plasty of foramen of Monro. Child's Nerv Syst 2008;24:933-942.

13. Tillmann BU, Emons D, Bartmann P, Fahnenstich H. Posthemorrhagic unilateral hydrocephalus: fenestration of septum pellucidum as an alternative to shunt implantation. J Pediatr 2004;144:126-128.

14. Oi S, Matsumoto S. Pathophysiology of non-neoplastic obstruction of the foramen of Monro and progressive unilateral hydrocephalus. Neurosurgery 1985;17:891-896.

15. Kehler U, Gliemroth J, Arnold H. Asymmetric hydrocephalus: safe endoscopic perforation of septum pellucidum: technical note. Minim Invas Neurosurg 1997:40:101-102.

16. Gangemi M, Maiuiri F, Cappabianca P, et al. Endoscopic fenestration of symptomatic septum pellucidum cysts. Three case reports with discussion on the approaches and technique. Minim Invas Neurosurg 2002;45: 105-108.

17. Vinas FC, Castillo C, Diaz FG. Microanatomical considerations for the fenestration of the septum pellucidum. Minim Invas Neurosurg 1998;41:20-26. 